\title{
Regression Models for Predictions of COVID-19 New Cases and New Deaths Based on May/June Data in Ethiopia
}

\author{
Alemayehu Argawu \\ Department of Statistics, Ambo University, Ambo, Ethiopia, P.O.Box 19
}

\begin{abstract}
BACKGROUND: On $15^{\text {th }}$ of June 2020, Ethiopia had 3,521 COVID-19 total cases, 60 total deaths $(1.7 \%), 620$ total recoveries (17.6\%), and 176 new cases. And, only 1,629 total tests were done per 1,000,000 populations. This study aimed to predict COVID-19 new cases and new deaths based on May/June data in Ethiopia using regression models. METHODS: In this study, correlation coefficient analysis and regression models were used for COVID19 new cases and new deaths data analysis based on the available data from $12^{\text {th }}$ May to $10^{\text {th }}$ June 2020 in Ethiopia. RESULTS: Both COVID-19 new cases and new deaths have correlated significantly with different COVID-19 related variables. In models comparison, the simple linear regression model was fitted better than quadratic and cubic regression models for both new cases and new deaths data. In the multiple linear regression model, new cases were predicted significantly by the number of days, daily laboratory tests, and Addis Ababa city new cases. And also, new deaths were predicted significantly by the number of days and new recoveries in the model.CONCLUSIONS: COVID-19 new case was predicted significantly by the number of days, daily laboratory tests and Addis Ababa city cases, and new deaths also predicted significantly by the number of days and new recoveries. The researcher recommended that government of Ethiopia, ministry of health, and regional governments should give more awareness and protections for societies, and they should open more laboratory testing centers. The researcher also recommended that time series models will be included for furthers.
\end{abstract}

Keywords: COVID-19, Number of Days, Laboratory Tests, Correlation Analysis, Regression Model

DOI: $10.7176 / \mathrm{JHMN} / 85-02$

Publication date: January $31^{\text {st }} 2021$

\section{INTRODUCTION}

\section{Background of the Study}

Coronavirus disease (COVID-19) was first identified on 31 December 2019 in the city of Wuhan, China. Some of the common signs of COVID-19 include fever, shortness of breath, and dry coughs. Other uncommon symptoms include muscle pain, mild diarrhea, abdominal pain, sputum production, loss of smell, and sore throat. On 11 March 2020, the WHO announced that it was a global pandemic (Hu et al. 2020; Tao et al. 2020; Wang et al. 2020; WHO 2020; WHO et al. 2020).

On $15^{\text {th }}$ of June 2020, as the Worldometer coronavirus updates information reported that we had 8,028,253 total COVID-19 cases, 436,276 total deaths with a 5.4\% fatality rate, and 4,148,128 total recovered with 51.7\% recovered rate as globally. Africa region had 244,578 total cases and 6,490 total deaths. And, Ethiopia had 3,521 COVID-19 total cases, 60 total deaths (1.7\%), 620 total recoveries (17.6\%) and 176 new cases as the Worldometer coronavirus updates information shown (Worldometer 2020).

This report also showed that Ethiopia was listed in $27^{\text {th }}$ place by the capacity of COVID-19 laboratory tests. And, only 1,629 total tests were done per 1,000,000 populations. This is bad news for Ethiopia. Currently, the Ethiopian population is near 115 million. This is the fact that Ethiopia has a very low proportion of COVID-19 laboratory tests compared with other countries' tests. This report indicated that Ethiopia needs increasing efforts and strategies to increase daily laboratory tests. And, this may indicate that Ethiopia will be one of the top 5 infected countries from the African region for the next few months. Thus, this study aimed to predict COVID-19 new cases and new deaths based on May/June data in Ethiopia using regression models.

\section{Literature Reviews}

Different studies from Indian, Algeria, Kenya and Philippine showed that there was a significant correlation between daily deaths and COVID-19 new cases, between daily deaths and dates, between daily deaths and number of daily recoveries, between dates and COVID-19 new cases, between number of laboratory tests with COVID-19 cumulative infected cases and cumulative deaths And, there was a strong correlation between weeks 5 and 6 death counts with total cases, active cases, recoveries, and week 4 death counts. Despite this, the week 4 variables (total cases, active cases, and recoveries) were not significantly predicted by weeks 5 and 6 deaths count. However, the week 4 death counts significantly predicted the week 5 death count. And, there was a correlation between COVID19 new cases and contact persons with confirmed status as well as the number of flights from foreign countries to Kenya (Anwar et al. 2020; Ghosal et al. 2020; Odhiambo et al. 2020; Montalban et al. 2020; Tadle et al. 2020; Yonar 2020).

And, similar studies from Indian found that the simple linear regression model was best to analyze the number 
of deaths as a function of the number of confirmed cases. In the model, the coefficient of determination was 0.997 , which implies a strong linear correlation between confirmed and dead cases. Whereas, the quadratic model was the best fitting model for Region II from April $6^{\text {th }}$ to May $2^{\text {nd }}$. And, another study from Kenya used the univariate analysis of the generalized linear model showed that contact persons in Kenya had 0.265 effects on COVID-19 cases in Kenya. In the multivariate analysis, the contact persons and flights to Kenya had 0.278 and 3,309 effects on COVID-19 cases in Kenya, respectively. And, the COVID-19 new cases were projected to 83,418 new cases if the COVID-19 days increased by 235 using the compound Poisson regression model (Chauhan et al. 2020; Odhiambo et al. 2020; Pasayat et al. 2020; Sharma and Nigam 2020).

\section{MATERIALS AND METHODS \\ Data}

The COVID-19 cases data was collected from the Ethiopia Ministry of Health Facebook and telegram pages (https://www.facebook.com/EthiopiaFMoH, \& https://t.me/MinistryOfHealthEthiopia). On 14 of March 2020, COVID-19 first case was confirmed in Ethiopia. The available data was considered from $12^{\text {th }}$ of May to the $10^{\text {th }}$ of June 2020.

\section{Correlation Coefficient}

Pearson's correlation coefficient is denoted as $\mathrm{r}$ for a sample statistic. For a correlation between variables $\mathrm{x}$ and $\mathrm{y}$, the formula for calculating the sample Pearson's correlation coefficient is given below (M.M Mukaka 2012).

$$
\mathbf{r}=\frac{\sum_{\mathrm{i}=\mathbf{1}}^{\mathrm{n}}\left[\left(\mathbf{X}_{\mathbf{i}}-\overline{\mathbf{X}}\right)\left(\mathbf{Y}_{\mathbf{i}}-\overline{\mathbf{Y}}\right)\right]}{\sqrt{\left[\sum_{\mathbf{i}=1}^{\mathrm{n}}\left(\mathbf{X}_{\mathbf{i}}-\overline{\mathbf{X}}\right)^{2}\right]\left[\sum_{\mathbf{i}=1}^{\mathrm{n}}\left(\mathbf{Y}_{\mathbf{i}}-\overline{\mathbf{Y}}\right)^{2}\right]}}
$$

Where: $X_{i}$ and $Y_{i}$ are values for variables $X$ and $Y$ for the $i^{\text {th }}$ individual, respectively. And, $\bar{X}$ and $\bar{Y}$ are means of the two variables.

\section{Regression Models}

Regression analysis is a statistical technique for investigating and modeling the relationship between variables. The regression model has many variants such as linear regression, polynomial regression, and other regressions (Douglas et al. 2012).

\section{Linear Regression Models}

The fitted simple linear regression model equation is written as follow:

$\widehat{\mathbf{Y}}=\mathbf{b}_{\mathbf{0}}+\mathbf{b}_{\mathbf{1}} \mathbf{X}_{\mathbf{1}}$

Where: $\widehat{Y}$ an estimated COVID-19 new cases. And $\mathrm{X}_{1}$ is an independent variable with its corresponding estimated coefficients $\left(b_{1}\right)$. And, $b_{0}$ is the intercept coefficient in the model.

The fitted multiple linear regression model equation is given as follow:

$\widehat{\mathbf{Y}}=\mathbf{b}_{\mathbf{0}}+\mathbf{b}_{\mathbf{1}} \mathbf{X}_{1}+\mathbf{b}_{2} \mathbf{X}_{2}+\mathbf{b}_{3} \mathbf{X}_{3}$

Where: $\widehat{Y}$ is the estimated COVID-19 new cases. And $\mathrm{X}_{1}, \mathrm{X}_{2}$, and $\mathrm{X}_{3}$ are independent variables with their corresponding estimated coefficients $\left(b_{1}, b_{2}\right.$, and $\left.b_{3}\right)$. And, $b_{0}$ is the intercept coefficient in the model.

\section{Polynomial Regression Models}

Polynomials are widely used in situations where the response is curvilinear, as even complex nonlinear relationships can be adequately modeled (Douglas et al. 2012). The estimated quadratic regression model or a second-order model in one variable is given as follow:

$\widehat{\mathbf{Y}}=\mathbf{b}_{\mathbf{0}}+\mathbf{b}_{\mathbf{1}} \mathbf{X}+\mathbf{b}_{\mathbf{2}} \mathbf{X}^{2}$

Where $\beta_{1}$ is the linear effect parameter and $\beta_{2}$ the quadratic effect parameter. The parameter $\beta_{0}$ is the mean of $Y$ when $X=0$ if the range of the data includes $X=0$. Otherwise $\beta_{0}$ has no physical interpretation.

In general, the kth-order polynomial model in one variable is

$\mathbf{Y}=\mathbf{b}_{\mathbf{0}}+\mathbf{b}_{1} \mathbf{X}+\mathbf{b}_{2} \mathbf{X}^{2}+\ldots+\mathbf{b}_{\mathbf{k}} \mathbf{X}^{\mathbf{k}}+\boldsymbol{\epsilon}$

Let $X_{j}=X^{j}, j=1,2, \ldots, k$, then Equation (5) becomes a multiple linear regression model in the k-regressors $X_{1}$, $\mathrm{X}_{2}, \ldots, \mathrm{X}_{\mathrm{k}}$. Thus, a polynomial model of order $\mathrm{k}$ may be fitted using the ordinary least-squares (OLS) estimates.

\section{RESULTS}

\section{Correlation Coefficient Analysis}

As shown in Table 1, The correlation coefficient analysis showed that the COVID-19 new cases have correlated positively and significantly with the number of days, daily laboratory tests, new cases of males, new cases of females, new cases from AA city, new cases from foreign natives, new cases with unknown contact and travel histories, and new cases with contact with infected persons. And also, new deaths of COVID-19 have correlated positively and significantly with the number of days, COVID-19 new cases, daily laboratory tests, new cases from 
AA city, new recoveries, new cases of males, and new cases of females and maximum age of new cases. However, it was correlated significantly but negatively with the minimum age of new cases.

Table 1: Correlation coefficient analysis between COVID-19 new cases, and new deaths with COVID-19 related variables

\begin{tabular}{|c|c|c|c|c|c|}
\hline \multirow{2}{*}{$\begin{array}{l}\text { COVID-19 } \\
\text { New Cases } \\
\text { (r \& p values) }\end{array}$} & $\begin{array}{l}\text { Number of } \\
\text { days }(0.901, \\
0.000)\end{array}$ & $\begin{array}{l}\text { Daily } \\
\text { laboratory tests } \\
(0.641,0.000)\end{array}$ & $\begin{array}{l}\text { New recoveries } \\
(0.389,0.034)\end{array}$ & $\begin{array}{l}\text { Males new cases } \\
(0.985,0.000)\end{array}$ & $\begin{array}{l}\text { Females new } \\
\text { cases } \\
(0.964,0.000)\end{array}$ \\
\hline & $\begin{array}{l}\text { AA city new } \\
\text { cases } \\
(0.965 \\
0.000)\end{array}$ & $\begin{array}{l}\text { New cases } \\
\text { from Foreign } \\
\text { Natives }(0.416, \\
0.022)\end{array}$ & $\begin{array}{l}\text { Cases had contact } \\
\text { with other } \\
\text { infected persons } \\
(0.534,0.010)\end{array}$ & \multicolumn{2}{|c|}{$\begin{array}{l}\text { Cases had unknown contact and } \\
\text { travel histories } \\
(0.958,0.000)\end{array}$} \\
\hline \multirow[t]{2}{*}{$\begin{array}{l}\text { New Deaths } \\
\text { (r \& p values) }\end{array}$} & $\begin{array}{l}\text { Number of } \\
\text { days } \\
(0.648 \\
0.000)\end{array}$ & $\begin{array}{l}\text { Laboratory } \\
\text { tests } \\
(0.445,0.014)\end{array}$ & $\begin{array}{l}\text { COVID-19 new } \\
\text { cases } \quad(0.555, \\
0.001)\end{array}$ & $\begin{array}{l}\text { Cases in AA city } \\
(0.533,0.002)\end{array}$ & $\begin{array}{l}\text { New } \\
\text { recoveries } \\
(0.753,0.000)\end{array}$ \\
\hline & $\begin{array}{l}\text { Males cases } \\
(0.530 \\
0.003)\end{array}$ & $\begin{array}{l}\text { Females cases } \\
(0.562,0.001)\end{array}$ & $\begin{array}{l}\text { Cases } \\
\text { minimum age }(- \\
0.426,0.019)\end{array}$ & \multicolumn{2}{|c|}{$\begin{array}{l}\text { Cases of maximum age }(0.400 \text {, } \\
0.028)\end{array}$} \\
\hline
\end{tabular}

\section{Models Comparison and Estimated Regression Models}

The model with the highest F-value, the smallest MSE value, and the highest R square value was better fit the data. Thus, the simple linear regression model was improved than the quadratic and cubic models as shown. And, COVID-19 new case was significantly predicted by the number of days, daily laboratory tests, and Addis Ababa city new cases. As shown in Table 2 and Figures 1-3, the estimated simple linear regression models for new cases of COVID-19 were written below.

New Cases $=-378.2+5.851 *$ number of the day. This implied that the new cases will be increased to 585 after 100 days.

New Cases $=-61+\mathbf{0 . 0 3 4} *$ daily laboratory tests. This indicated that the new cases will be raised to 3,400 if 100,000 laboratory tests are conducted daily.

New Cases $=10.8+1.2 *$ Addis Ababa city new cases. This suggested that the country new cases will be highly increased to 12,000 if 10,000 new cases are recorded in Addis Ababa city.

And, new death of COVID-19 was significantly predicted by the number of days, new cases, and new recovery. As shown in Table 3 and Figures 4-6, the estimated simple linear regression models for new deaths of COVID-19 were written below.

New Deaths $=-8.6+0.12 *$ number of days. This showed that the new deaths will be increased to 12 after 100 days.

New Deaths $=0.016 *$ New Cases. This indicated that the new deaths will be raised to 16 if 1,000 new cases are recorded.

New Cases $=0.1 *$ new recovery. This implied that the new deaths will be increased to 100 if 1,000 patients recovered from the virus.

Table 2: Regression models summaries and parameter estimates to predict COVID-19 new cases.

\begin{tabular}{|c|c|c|c|c|c|c|c|c|c|}
\hline $\begin{array}{c}\text { Inde'pt } \\
\text { Variable }\end{array}$ & Model & $\mathrm{R}^{2}$ & $\mathrm{~F}$ & MSE & Sig. & Constant & b1 & $\mathrm{b} 2$ & b3 \\
\hline \multirow[t]{3}{*}{ Day } & Linear & 0.81 & 120.7 & 637.4 & 0.000 & $-378.2(0.000)$ & $5.851(0.000)$ & & \\
\hline & Quadratic & 0.82 & 59.8 & 646.3 & 0.000 & $-55.7(0.894)$ & $-2.577(0.813)$ & $0.054(0.440)$ & \\
\hline & Cubic & 0.82 & 59.8 & 646.3 & 0.000 & $-55.7(0.894)$ & $-2.577(0.813)$ & $0.054(0.440)$ & 0 \\
\hline \multirow{3}{*}{$\begin{array}{l}\text { Daily } \\
\text { Laborato } \\
\text { ry Tests }\end{array}$} & Linear & 0.41 & 19.5 & $\begin{array}{c}1993 . \\
3\end{array}$ & 0.000 & $-61.0(0.000)$ & $0.034(0.000)$ & & \\
\hline & Quadratic & 0.43 & 10.4 & $\begin{array}{c}1983 . \\
8\end{array}$ & 0.000 & $37.0(0.707)$ & $-0.017(0.722)$ & 0 & \\
\hline & Cubic & 0.46 & 7.5 & $\begin{array}{c}1952 . \\
2\end{array}$ & 0.001 & $338.8(0.220)$ & $-0.273(0.223)$ & $0.0001(0.204)$ & 0 \\
\hline \multirow{3}{*}{$\begin{array}{l}\text { Addis } \\
\text { Ababa } \\
\text { City New } \\
\text { Cases }\end{array}$} & Linear & 0.93 & 382.6 & 230.8 & 0.000 & $10.8(0.000)$ & $1.2(0.000)$ & & \\
\hline & Quadratic & 0.93 & 187.4 & 235.9 & 0.000 & $9.1(0.090)$ & $1.3(0.000)$ & $-0.001(0.533)$ & \\
\hline & Cubic & 0.93 & 122.3 & 241.2 & 0.000 & $7.02(0.262)$ & $1.6(0.006)$ & $-0.007(0.469)$ & 0 \\
\hline
\end{tabular}


Estimated Multiple Linear Regression Models for COVID-19 new cases

As shown the R-software output in Figure 7, COVID-19 new cases were predicted significantly by Addis Ababa city new cases, the number of days, and daily laboratory tests in the multiple linear regression models. The $\mathrm{R}^{2}=96 \%$ of the variation in COVID-19 new cases was explained by the predictors. In the hypothesis test (F-statistic=205.1 with $\mathrm{DF}=3 \& 26$, p-value=0.000), there was enough evidence to reject the null hypothesis that all the model's coefficients are 0 . The residual standard error $=12.16$ showed how far the observed total COVID-19 new cases (Y-values) from the predicted COVID-19 new cases $\widehat{Y}$.

And the estimated model was written as COVID $-\overline{19 N}$ ew Cases $=-99.1+1.352 *$ number of days + $0.00503 *$ daily laboratory tests $+\mathbf{0 . 8 8 0 9 6} *$ new cases from AA city.

Thus, COVID-19 new cases will be increased to 135 new cases when the number of days increases by 100 days while holding other variables constant. And, the COVID-19 new cases will be increased to 503 when the daily laboratory tests rise by 100,000 tests. Similarly, the COVID-19 new cases will be increased to 881 when Addis Ababa city new cases increase by 10,000 cases.

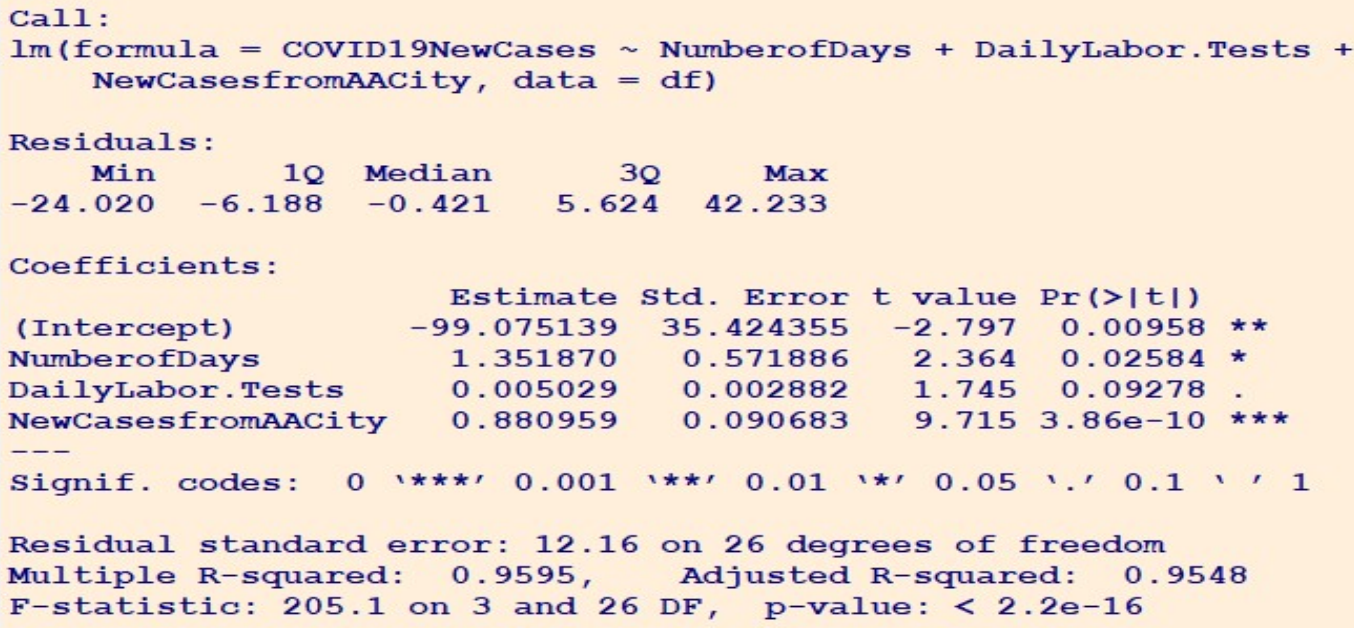

Figure 7: Multiple linear regression model for estimating the parameter to predict New Cases.

Estimated Multiple Linear Regression Model for New Deaths

As shown in Figure 8, new deaths of COVID-19 were predicted significantly by new recoveries, and the number of days in the multiple linear regression models. The $\mathrm{R}^{2}=62.4 \%$ of the variation in new deaths was explained by the predictors. In the hypothesis test (F-statistic $=22.4$ with $\mathrm{DF}=2 \& 27$, p-value $=0.000)$, there was enough evidence to reject the null hypothesis that all the model's coefficients are 0 . The residual standard error $=1.07$ shows how far the observed new deaths (Y-values) from the predicted new deaths $\widehat{Y}$.And, the estimated model was given as New Deaths $=-4.22+0.057 *$ number of days $+\mathbf{0 . 0 7 8 9} *$ new recoveries.

This provides that new deaths of COVID-19 will be increased to 79 deaths when the new recoveries rise by 1,000 recoveries with holding other variables constant. And, the new deaths will be increased by 6 deaths when the number of days increases by 100 days.

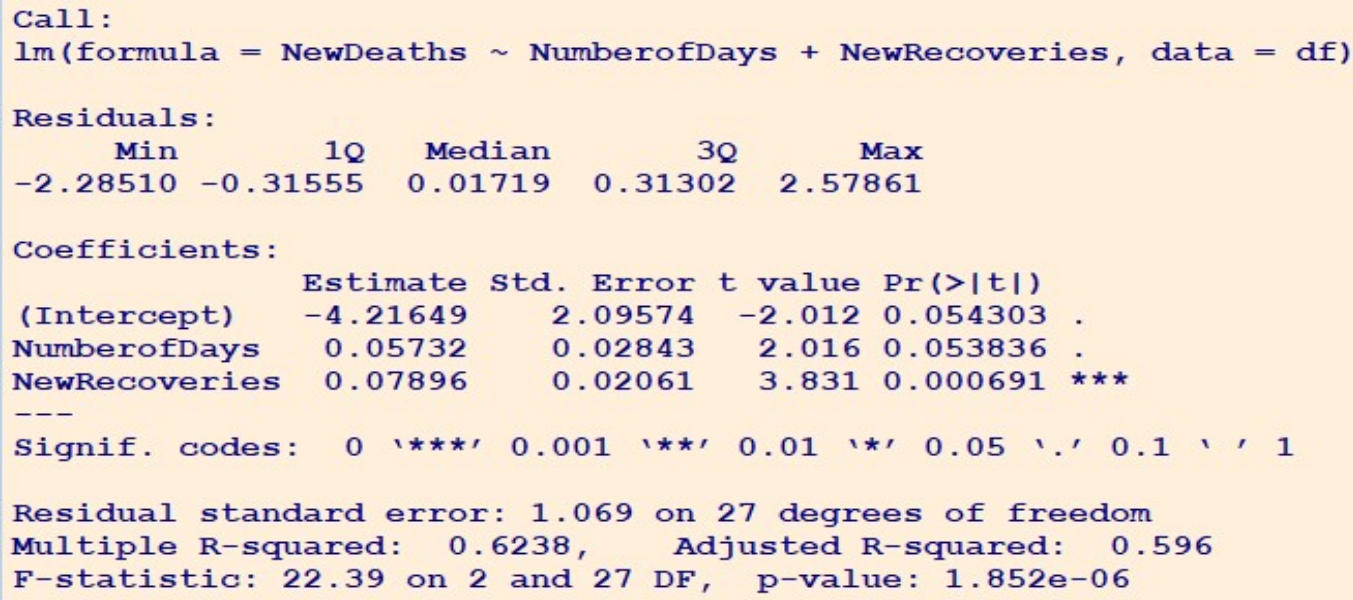

Figure 8: Multiple linear regression model for estimating the parameter to predict new deaths. 


\section{DISCUSSIONS}

In this study, the correlation coefficient analysis showed that COVID-19 new cases have correlated significantly and positively with the number of days, daily laboratory tests, new recoveries, males new cases, females new cases, Addis Ababa city new cases, new cases from foreign natives, new cases had unknown contact and travel histories, and new cases had contacts with infected persons. And, new deaths of COVID-19 have correlated significantly and positively with the number of days, COVID-19 new cases, daily laboratory tests, Addis Ababa city new cases, new recoveries, males' new cases, females' new cases, and the maximum age of new cases. But, it was correlated significantly and negatively with the minimum age of new cases.

This study correlation analysis findings are agreed with different studies from Indian, Algeria, Kenya and Philippine showed that there was a significant correlation between daily deaths and COVID-19 new cases, between daily deaths and dates, between daily deaths and number of daily recoveries, between dates and COVID-19 new cases, between number of laboratory tests with COVID-19 cumulative infected cases and cumulative deaths And, there was a strong correlation between weeks 5 and 6 death counts with total cases, active cases, recoveries, and week 4 death counts. Despite this, the week 4 variables (total cases, active cases, and recoveries) were not significantly predicted by weeks 5 and 6 deaths count. However, the week 4 death counts significantly predicted the week 5 death count. And, there was a correlation between COVID-19 new cases and contact persons with confirmed status as well as the number of flights from foreign countries to Kenya (Anwar et al. 2020; Ghosal et al. 2020; Odhiambo et al. 2020; Montalban et al. 2020; Tadle et al. 2020; Yonar 2020).

In this study, the simple linear regression model was a better fit for the data of COVID-19 new cases and new deaths than quadratic and cubic regression models. In this fitted model, COVID-19 new cases were significantly predicted by the number of days, daily laboratory tests, and new cases from Addis Ababa city. And, new deaths were significantly predicted by the number of days, new cases, and new recovered. In the multiple linear regression models, COVID-19 new cases were predicted significantly by the number of days, daily laboratory tests, and new cases from Addis Ababa city.

This study models fitting are agreed with similar studies from Indian and Kenya. The simple linear regression model was best to analyze the number of deaths as a function of the number of confirmed cases. In the model, the coefficient of determination was 0.997 , which implies a strong linear correlation between confirmed and dead cases. Whereas, the quadratic model was the best fitting model for Region II from April $6^{\text {th }}$ to May $2^{\text {nd }}$. And, another study from Kenya used the univariate analysis of the generalized linear model showed that contact persons in Kenya had 0.265 effects on COVID-19 cases in Kenya. In the multivariate analysis, the contact persons and flights to Kenya had 0.278 and 3,309 effects on COVID-19 cases in Kenya, respectively. And, the COVID-19 new cases were projected to 83,418 new cases if the COVID-19 days increased by 235 using the compound Poisson regression model (Chauhan et al. 2020; Odhiambo et al. 2020; Pasayat et al. 2020; Sharma and Nigam 2020).

\section{Conclusions}

The researcher concluded that both COVID-19 new case and new deaths were correlated significantly with different COVID-19 related variables (like number of days, daily laboratory tests, new recoveries, and etc.). And, linear regression model was better fit for both COVID-19 new cases and new deaths as compared quadratic and cubic regression models. And, COVID-19 new cases was predicted significantly by the number of days, daily laboratory tests, and Addis Ababa city new cases in the multiple linear regression model. And, new death of COVID-19 was predicted significantly by the number of days, and new recoveries in the model.

\section{Recommendations}

The researcher recommended that government of Ethiopia, the country ministry of health and all regional governments (especially Addis Ababa city administrative and Somali region) should give more awareness and protections collaboratively for societies, and they should also open more COVID-19 laboratory testing centers in different areas of the country to test more persons as the number of days increases, and the number of new cases will be highly increased. With these preventive and curative measures, the severity of COVID-19 will be limited when compared to other countries, such as the USA, and South Africa, which are now leading in the number of new cases and deaths in the world and African countries. And, the researcher recommended that time series model will be included for future study.

\section{Limitations of the Study}

The main limitation of this study was that the study was based on only 30 days of COVID-19 new cases and new deaths data from $12^{\text {th }}$ of May to $10^{\text {th }}$ of June 2020 in Ethiopia. Second, limiting my analysis was that some data values were missed to report for 8 days (for the contact and travel history of the patients).

\section{Strengths of the Study}

Despite all the limitations, the greatest strength of this study was that the new findings were found that are three 
predictors (number of days, daily laboratory tests, and Addis Ababa city new cases) for COVID-19 new cases and two predictors (number of days, and daily laboratories tests) for new deaths of COVID-19. And, other new findings in this study was both COVID-19 new cases and new deaths of COVID-19 have correlated significantly with the number of days, daily laboratory tests, Addis Ababa city new cases, new recoveries, and with other COVID-19 related variables. Also, there was cross-validation with two different software programs (R and SPSS). Thus, all these findings were filled the gaps of other related studies mentioned above.

\section{ACKNOWLEDGMENTS}

I would like to extend my gratitude to the Ethiopian Federal Minister of Health (Dr. Liya Tadesse) for posting the COVID-19 cases reports daily in her Facebook and telegram pages.

(https://www.facebook.com/EthiopiaFMoH, \& https://t.me/MinistryOfHealthEthiopia).

And, I said thanks Ambo University for internet access.

\section{Data Availability}

The data are available if it is required.

\section{Funding}

The research work was not supported by anyone.

Declaration of Competing Financial Interests

The author declares that he has no actual or potential competing financial interests.

Author contributions

All the research's sections were performed by Argawu A. He was the only author of this study.

\section{REFERENCES}

Anwar, Benabdellah, Brahimi Houria, Bensaad Mohamed, Labdouni Mohamed El-habib, Labdelli Nada, Benabdelkader Maghnia, Benabdellah Yasmine, et al. 2020. "IMedPub Journals Correlation between New Daily COVID-19 Cases , New Daily Deaths and Google Trends for Masks in Algeria” 2020 (Figure 1): 1012. https://doi.org/10.36648/1989-5216.12.4.319.

Chauhan, Poonam, Ashok Kumar, Pooja Jamdagni, and Departmentof Physics. 2020. "Regression Analysis of COVID-19 Spread in India and Its Different States" 2020 (June): 1-14. https://doi.org/10.1101/2020.05.29.20117069.

Douglas C. Montgomery, Elizabeth A. Peck, G. Geoffrey. 2012. Introduction to Linear Regression Analysis. A JOHN WILEY \& SONS, INC., PUBLICATION. https://www.academia.edu/32079757.

Ghosal, Samit, Sumit Sengupta, Milan Majumder, and Binayak Sinha. 2020. "Prediction of the Number of Deaths in India Due to SARS-CoV-2 at 5-6 Weeks." Diabetes and Metabolic Syndrome: Clinical Research and Reviews 14 (4): 311-15. https://doi.org/10.1016/j.dsx.2020.03.017.

Hu, Zixin, Qiyang Ge, Shudi Li, Li Jin, and Momiao Xiong. 2020. "Artificial Intelligence Forecasting of Covid19 in China," no. April. http://arxiv.org/abs/2002.07112.

M.M Mukaka. 2012. "Statistics Corner: A Guide to Appropriate Use of Correlation Coefficient in Medical Research." Malawi Medical Journal 24 (3): 69-71. https://pubmed.ncbi.nIm.nih.gov/23638278/.

Montalban, Erl Jay, Richard Canja, Razer Caluban, and Mark Van Buladaco. 2020. "Correlational Analysis of COVID-19 Deaths and Recoveries per Country," no. June. https://doi.org/10.2139/ssrn.3624543.

Odhiambo, Joab O., Philip Ngare, Patrick Weke, and Romanus Odhiambo Otieno. 2020. "Modelling of COVID19 Transmission in Kenya Using Compound Poisson Regression Model." Journal of Advances in Mathematics and Computer Science, no. May: 101-11. https://doi.org/10.9734/jamcs/2020/v35i230252.

Pasayat, Ajit Kumar, Satya Narayan Pati, and Aashirbad Maharana. 2020. "Predicting the COVID-19 Positive Cases in India with Concern to Lockdown by Using Mathematical and Machine Learning Based Models." MedRxiv, 2020.05.16.20104133. https://doi.org/https://doi.org/10.1101/2020.05.16.20104133.

Sharma, Vikas Kumar, and Unnati Nigam. 2020. "Modelling of Covid-19 Cases in India Using Regression and Time Series Models," no. around 168500. https://doi.org/10.1101/2020.05.20.20107540.

Tadle, Julie Anne, Chloe Mhae Regalado, Ryl John De Jesus, and Mark Van Buladaco. 2020. "Correlational Analysis of COVID-19 Number of Daily New Cases and Number of Daily Deaths per Day: A Case in the Philippines.” SSRN Electronic Journal, no. January. https://doi.org/10.2139/ssrn.3624526.

Tao, Zhao-wu, Jun-hua Tian, Yuan-yuan Pei, Ming-li Yuan, Yu-ling Zhang, and Fa-hui Dai. 2020. "A New Coronavirus Associated with Human Respiratory Disease in China" 579 (January). https://doi.org/10.1038/s41586-020-2008-3.

Wang, Yunlu, Menghan Hu, Qingli Li, Xiao-Ping Zhang, Guangtao Zhai, and Nan Yao. 2020. “Abnormal 
Respiratory Patterns Classifier May Contribute to Large-Scale Screening of People Infected with COVID19 in an Accurate and Unobtrusive Manner." http://arxiv.org/abs/2002.05534.

WHO. 2020. "WHO Director-General's Opening Remarks at the Media Briefing on COVID-19 - 11 March 2020." WHO Director General's Speeches, no. March: 4. https://www.who.int/dg/speeches/detail/who-directorgeneral-s-opening-remarks-at-the-media-briefing-on-covid-19---11-march-2020.

WHO, Aylward, Bruce, and Liang. 2020. "Report of the WHO-China Joint Mission on Coronavirus Disease 2019 (COVID-19)." The WHO-China Joint Mission on Coronavirus Disease 20192019 (February): 1624.https://www.who.int/docs/default-source/coronaviruse/who-china-joint-mission-on-covid-19-finalreport.pdf.

Worldometer. 2020. “Coronavirus Cases.” Worldometer, 1-22. https:/www.worldometers.info/coronavirus/? Yonar, Harun. 2020. "Modeling and Forecasting for the Number of Cases of the COVID-19 Pandemic with the Curve Estimation Models, the Box-Jenkins and Exponential Smoothing Methods." Eurasian Journal of Medicine and Oncology 4 (2): 160-65. https://doi.org/10.14744/ejmo.2020.28273.

Figures

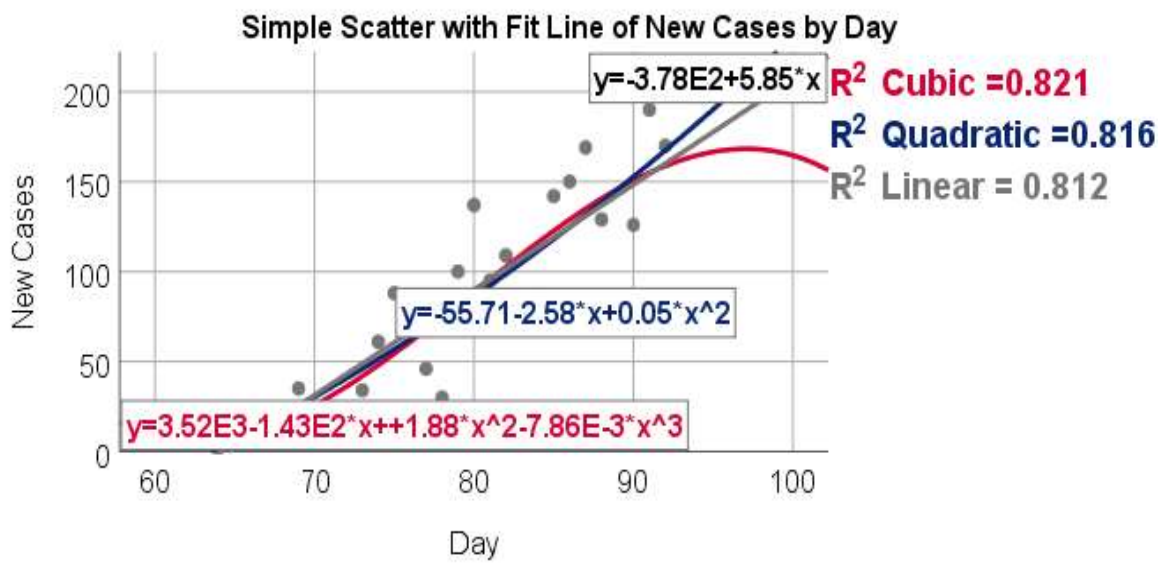

Figure 1. Curve estimation model for COVID-19 new cases by the number of days.

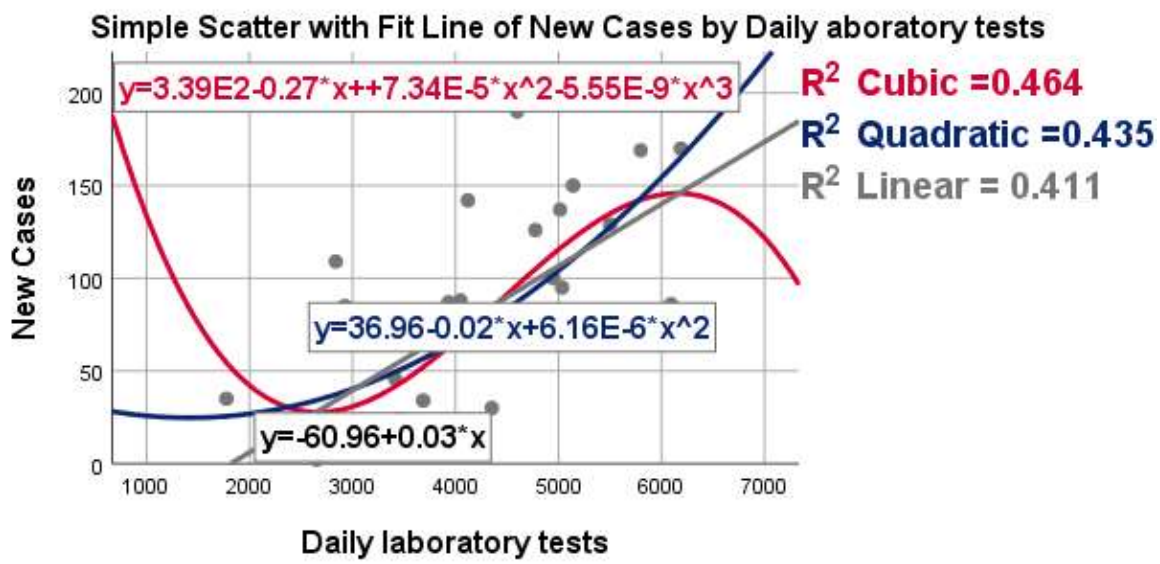

Figure 2. Curve estimation model for COVID-19 new cases by daily laboratory tests. 


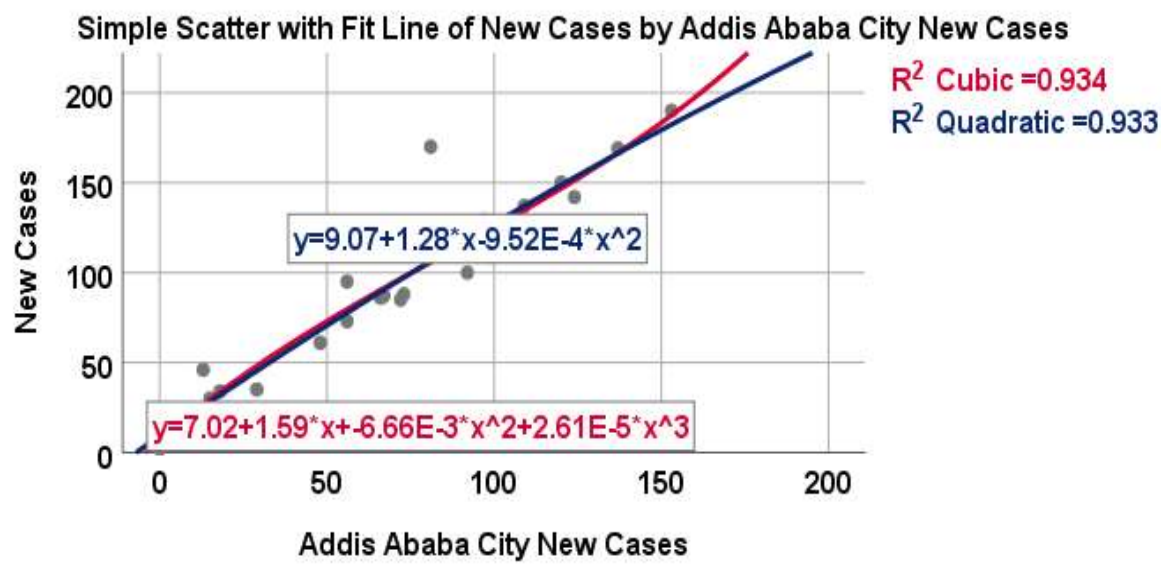

Figure 3. Curve estimation model for COVID-19 new cases by new cases from AA city.

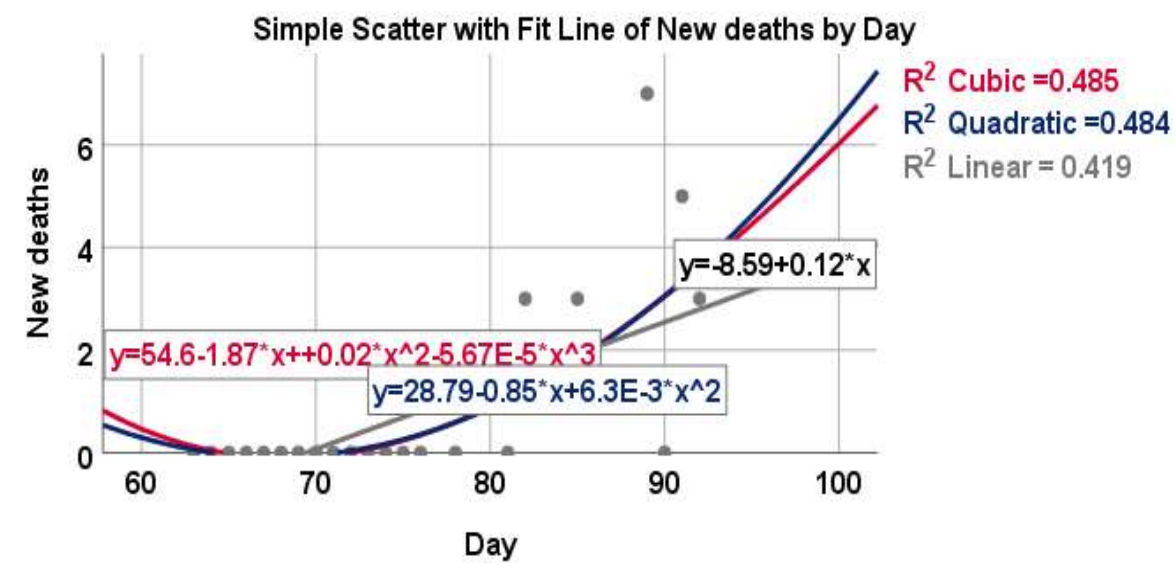

Figure 4. Curve estimation model for new deaths of COVID-19 by the number of days.

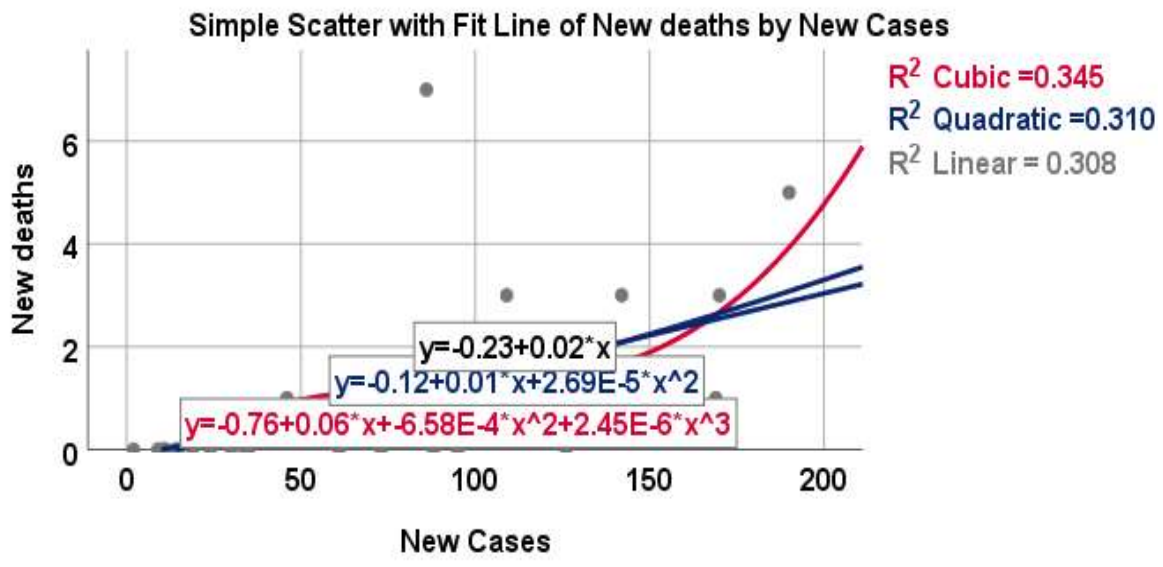

Figure 5. Curve estimation model for new deaths of COVID-19 by new cases. 


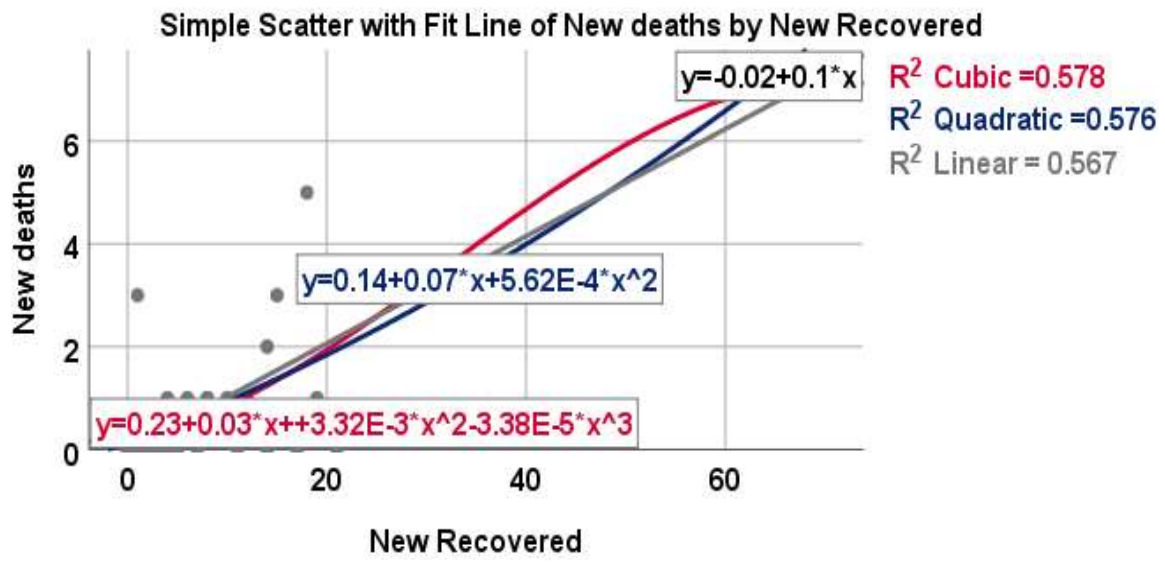

Figure 6. Curve estimation model for new deaths of COVID-19 by new recovery. 